\title{
Espiritualidade e saúde mental no contexto do aconselhamento pastoral
}

Neir Moreira da Silva ${ }^{1}$

\section{RESUMO}

Esse artigo tem por objetivo abordar as implicações estabelecidas por meio da espiritualidade e saúde mental no contexto e práxis do aconselhamento pastoral a partir da realidade do contexto religioso pentecostal. Os dados analisados fazem parte da pesquisa realizada com pastores pentecostais da cidade de Curitiba no ano de 2012. A partir da fundamentação bíblico-teológica e outros saberes, em especial a psicologia, o autor propõe a compreensão do sofrimento humano sob a perspectiva da promoção da saúde mental bem como por meio da vivência e manifestação da espiritualidadehumana. $\mathrm{O}$ artigo tambémdestaca e distingue a importância do aconselhamento de pastores e do aconselhamento a pastores como uma proposta viável de saúde integral do ser humano, especialmente daqueles que dedicam suas vidas ao socorro espiritual.

\section{PALAVRAS-CHAVE}

Espiritualidade. Saúde Mental. AconselhamentoPastoral.

\footnotetext{
${ }^{1}$ Neir Moreira da Silva. Mestre em Teologia pela Pontifícia Universidade Católica do Paraná, Pós-Graduado em Docência do Ensino Religioso pela Faculdade Batista do Paraná, Bacharel em Psicologia pela Universidade Federal do Paraná, membro do corpo docente das Faculdades Cristã de Curitiba, Facel, e São Bráz.
} 


\section{ABSTRACT}

The objective of this paper is to approach the established implications through spirituality and mental health in the context and praxis of pastoral counseling from the reality of Pentecostal religious context. The investigated data are linked to a research carried out with Pentecostal pastors in Curitiba in 2012. Starting from a biblical-theological ground and other areas of knowledge, especially Psychology, the author presents the comprehension of human suffering from the perspective of mental health promotion as well as through the experience and manifestation of human spirituality. The paper also points out and distinguishes the importance of pastor counseling and of counseling pastors as a viable proposal of human being's overall health, particularly of those people who dedicate their lives to spiritual care.

\section{KEYWORDS}

Spirituality. Mental Health. Pastoral Counseling.

Historicamente, o espaço do aconselhamento pastoral tem sido ocupado por dois tipos de sujeitos: os que cuidam e os que são cuidados. Via de regra, o conselheiro pastoral assume o lugar de acolhedor. Tanto de pessoas quanto de conflitos. Esse artigo se propõe a questionar o devido lugar que os cuidados de pessoas devam assumir enquanto sujeitos humanos, além de resgatar a importância da espiritualidade e religiosidade no campo da saúde mental. Ademais, com uma questão em aberto sobre o sentido do sofrimento, o texto se desenvolve no intuito de permitir uma reflexão sobre a mão dupla do aconselhamento pastoral e de pastores em aconselhamento.

\section{Espiritualidade e Religiosidade em Saúde Mental}

Historicamente, além da teologia, outras ciências também têm se debruçado sobre as implicações que religião impõe sobre as pessoas, incluindo a psicologia. Os achados dão conta que a experiência reli- 
giosa, em geral, produz resultados satisfatórios tanto para os sujeitos envolvidos nessa prática quanto para os demais que, de alguma forma, são influenciados pelas consequências desse envolvimento.

[...] A tarefa das ciências humanas na Teologia Prática é ajudar no entendimento do elemento empírico para promover a inculturação do evangelho. Para estabelecer as propostas teológicas básicas precisa-se de um diálogo com as outras disciplinas da teologia e com as ciências humanas. A relação entre teologia e ciências humanas se caracteriza por crítica mútua. A teologia questiona os princípios metodológicos e os resultados da pesquisa das ciências a partir de princípios teológicos estabelecidos num discurso entre os sujeitos da práxis. As ciências humanas questionam os princípios teológicos e a prática religiosa empírica a partir dos seus princípios aceitos ou estabelecidos num discurso entre os sujeitos da práxis ${ }^{2}$.

Frankl, por sua vez, aprofunda o tema da totalidade humana. Para ele, "pelo fato de o ser humano estar centrado como indivíduo em uma pessoa determinada (como centro espiritual existencial), e somente por isso, o ser humano é também um ser integrado: somente a pessoa espiritual estabelece a unidade e totalidade do ente humano"3. Sendo assim, a pessoa espiritual assume a totalidade e amplitude bio-psico-espiritual. E, a esta totalidade (ao gênero humano total), pertence o espiritual, bem como a sua característica específica.

Em Frankl, a concepção psicológica da religião relaciona-se com uma avaliação positiva do ato de fé. Sendo assim, tanto na teologia judaica como na teologia cristã contemporânea de matriz existencial, esse ato de fé é percebido como o momento no qual o ser humano se possui enquanto totalidade e completude de sua existência. "É o que se pode resumir como auto-posse em liberdade e auto-

\footnotetext{
${ }^{2}$ SCHNEIDER-HARPPRECHT, Christoph. Teologia Prática no Contexto da América Latina (org.). São Leopoldo: Sinodal/ASTE, 1998, p. 59.

${ }^{3}$ FRANKL, Viktor Emil. A presença ignorada de Deus. Tradução: Walter O. Schlupp e Helga H. Reinhold. São Leopoldo: Editora Sinodal; Petrópolis: Editora Vozes, 2003, p. 21.
} 
-disposição como resposta a uma missão"4. Embora seja uma dádiva divina, a fé é um dos atributos requeridos para uma vida plena em relação a Deus.

Atualmente, pesquisadores da interface entre psicologia e teologia têm resgatado o conceito etimológico de religião, ou seja, re-ligar. O re-ligar do ser humano e suas dimensões essenciais equivale ao seguinte, pelo viés da teologia e da psicologia: "a religião, a Deus; a psicologia, a si mesmo e às suas fontes mais genuínas" ${ }^{\text {. Evidente- }}$ mente, o ato da re-ligação do humano a Deus exigirá recursos disponíveis tanto do indivíduo quanto dos envolvidos na prática religiosa em questão. Para Frankl ${ }^{6}$, a concepção de religião, no sentido amplo do termo, não tem nada a ver com mesquinhez confessional e sua consequência, ou seja, a miopia religiosa, a qual aparentemente vê em Deus um Ser cujo único objetivo é conseguir que o maior número possível de pessoas acredite nele, exatamente dentro das prescrições eclesiásticas ou institucionais.

De acordo com Aletti $^{7}$, a religiosidade pode ser considerada uma relação madura com um Deus significativo do ponto de vista psicodinâmico, isso equivale afirmar, uma representação divina integrada e coerente com o conjunto psíquico do sujeito. Para ele, a vivência religiosa consiste num dos aspectos da personalidade, a qual deve ser harmonizada em relação aos demais aspectos. Para $\mathrm{Frank}^{8}$, "a verdadeira religiosidade não tem caráter de impulso, mas antes de decisão".

${ }^{4}$ LONERGAN, 1978 apud HOLANDA, Adriano. Psicologia, religiosidade e fenomenologia. Organizador. Campinas, SP: Editora Alínea, 2004, p. 141.

${ }^{5}$ HOLANDA, 2004, p. 144.

${ }^{6}$ FRANKL, 2003, p. 87.

${ }^{7}$ ALETTI, Mario. Atendimento psicológico e direção espiritual: semelhanças, diferenças, integrações e... confusões. Psicologias: Teoria e Pesquisa. Vol. 24, n. 1, 2008, p. 121.

${ }^{8}$ FRANKL (2003, p. 56) apud MOREIRA, Neir \& HOLANDA, Adriano. Logoterapia e o sentido do sofrimento: convergências nas dimensões espiritual e religiosa. Revista Psico-USF [online]. Vol. 15, n. 3 [Acesso em 08 de maio de 2012], 2010, p. 353 . 
Faz-se necessária distinguir os termos religiosidade e espiritualidade, embora sejam utilizados como sinônimos em muitos contextos. Religiosidade tem o cunho institucionalmente socializado e é vinculado a uma doutrina coletivamente compartilhada, e, espiritualidade refere-se às práticas subjetivas, individuais e não necessariamente institucionais. "A conceituação de religiosidade inclui aspectos individuais e institucionais, enquanto espiritualidade é um fenômeno apenas individual, identificado com aspectos como transcendência pessoal, sensibilidade 'extraconsciente' e fonte de sentidos para eventos na vida". Admite-se também que tanto a espiritualidade quanto a religiosidade seriam mais amplos que o termo religião.

Para Drakeford, os aspectos positivos entre a religião e a saúde mental são os seguintes: a religião pode oferecer às pessoas um senso de segurança, ela pode motivar a vida, ela também pode auxiliar as pessoas a aceitarem a si mesmas, pode possibilitar a experiência da confissão, igualmente tem a possibilidade de oferecer estabilidade emocional em tempos de crises, bem como ela pode permitir às pessoas uma comunidade de caráter terapêutico ${ }^{10}$.

De acordo com as pesquisas recentes, os melhores resultados no campo da saúde mental - especialmente na prevenção da depressão e do estresse - relacionam as variáveis religião e saúde. De acordo com um estudo sobre os fatores associados à depressão em idosos na comunidade de Barra Funda, no Rio Grande do Sul, evidenciou que a pouca incidência de depressão entre os idosos tinha na religiosidade um fator de proteção ${ }^{11}$. No entanto, é necessário enfatizar que os resultados das pesquisas afirmam que a religiosidade pode mostrar-se tanto positiva quanto nega-

${ }^{9}$ FARIA, Juliana Bernardes de \& SEIDL, Eliane Maria Fleury. Religiosidade e enfrentamento em contextos de saúde e doença: revisão da literatura.Psicologia: Reflexão e Crítica. Universidade de Brasília. vol.18, n.3, 2005, pp. 381-389. Disponível em: $\quad<$ http://www.scielo.br/scielo.php?script=sci arttext\&pid=S0102$-79722005000300012 \& \operatorname{lng}=$ pt\&nrm=iso\&tlng=pt. Acesso em: 17 fev. 2012, p. 381.

${ }^{10}$ DRAKEFORD (1964) apud ROSA, Merval. Psicologia da religião. Rio de Janeiro: JUERP, 1992, pp. 234-236.

${ }^{11}$ DIAS, Agemir de Carvalho. Religião e saúde: uma contribuição evangélica. Revista Pistis\&Praxis - Teologia e Pastoral. Curitiba, v. 2, jan./jun. 2010, p. 132. 
tivamente. Em um estudo revisional sobre saúde mental, a religiosidade mostrou-se positiva na metade dos casos, e negativa em $25 \%$ deles ${ }^{12}$.

Vale salientar que o encontro pessoal do indivíduo com Deus e a união entre ambos constituem a base de toda religião autêntica. Pode-se dizer que isso pressupõe a presença de um poder transformador e "um voltar-se do ser humano para aquilo que é último, abandonando todas as preocupações preliminares"13.

Uma religião é verdadeira e boa na medida em que serve à humanidade, uma vez em que suas doutrinas de fé e de moral em seus ritos e instituições fomenta a identidade, a sensibilidade e os valores humanos, permitindo assim ao ser humano alcançar uma existência rica e plena, e uma religião é falsa e má na medida em que provoca desumanidade opondo-se através de suas doutrinas de fé e de moral, de seus ritos e instituições à identidade, à sensibilidade e aos valores humanos e contribuindo assim para que o ser humano frustre uma existência rica e plena ${ }^{14}$.

A rigor, uma religião sadia pode se constituir num fator de grande importância no equilíbrio emocional do ser humano. "Indivíduos de profunda convicção e experiência religiosas resistem melhor às pressões da vida"15.

Uma observação precisa ser destacada. A relação entre religião e saúde, notadamente no contexto eclesiástico, pode evidenciar um equívoco quando se emparelha termos como "saúde" e "santidade". Eventualmente esses conceitos são admitidos como sinônimos. Em contrapartida,Sudbrack ${ }^{16}$ resume numa afirmação o paradoxo que isso pode revelar. Para esse autor, "a fragilidade psíquica pode andar de

\footnotetext{
${ }^{12}$ FLECK (2003, p. 447), apud DIAS, 2010, p. 131.

${ }^{13}$ TILLICH, Paul. Teologia Sistemática. Tradução: Getúlio Bertelli e Geraldo Korndörfer. São Leopoldo: Sinodal, 2011, p. 378.

${ }^{14}$ KÜNG (1999, p. 279), apud DIAS, 2010, p. 134.

${ }^{15}$ ROSA, 1992, p. 227.

${ }^{16}$ SUDBRACK, Josef. Experiência religiosa e psique humana: onde a religião e a psicologia se encontram. Tradução: FredericusAntonius Stein. São Paulo: Edições Loyola, 2001, pp. 46,51.
} 
mãos dadas com a santidade". Uma pessoa santa não está imune às neuroses. Isso pode soar exagerado e até impróprio, mas significa uma ruptura no modo de compreensão da relação fé e saúde.Oregistro bíblico narra mulheres ehomens santos os quais, a despeito de sua conduta reta e fiel à Deus, não foram isentados da possibilidade de serem acometidos por enfermidades físicas e psíquicas.

O apóstolo Paulo ${ }^{17}$, um dos ícones do Novo Testamento, serve como exemplo a ser lembrado. Apesar de não se ter um diagnóstico absolutamente claro sobre a sua saúde (ou falta dela), o fato é que a mesma pessoa acometida de um "espinho na carne" também era o mesmo sujeito que "foi arrebatado ao paraíso; e ouviu coisas inefáveis"18. Segundo Sudbrack ${ }^{19}$, a morada de Deus não costuma ser num corpo sadio. O apóstolo Paulo chegou afirmou que a graça de Deus se aperfeiçoa na fraqueza. Evidentemente, essa fragilidade pode assumir dimensões físicas, psíquicas e espirituais.

Vale salientar que, na perspectiva da ciência psicológica, "a saúde existencial consiste no bem-estar geral que cada um de nós experiencia no decorrer da própria existência, caracterizado por uma vivência global de liberdade, acolhimento e sintonia em relação a si, aos seus semelhantes e ao mundo em geral" ${ }^{20}$. Para essa autora, há uma linha tênue entre saúde e doença existencial:

Saúde e adoecimento existenciais fazem parte da vida de todos nós. São como dois polos constituintes da totalidade da existência.

\footnotetext{
17 "E, para que não me exaltasse pela excelência das revelações, foi-me dado um espinho na carne, a saber, um mensageiro de Satanás para me esbofetear, a fim de não me exaltar. Acerca do qual três vezes orei ao Senhor para que se desviasse de mim. E disse-me: A minha graça te basta, porque o meu poder se aperfeiçoa na fraqueza. De boa vontade, pois, me gloriarei nas minhas fraquezas, para que em mim habite o poder de Cristo" (2 Coríntios 12:7-9).

182 Coríntios 12.4.

${ }^{19}$ SUDBRACK, Josef. Experiência religiosa e psique humana: onde a religião e a psicologia se encontram, pp. 51,52.

${ }^{20}$ BOSS (1983, p. 123), apud FORGHIERI, Yolanda Cintrão. Aconselhamento terapêutico: origens, fundamentos e prática. São Paulo: Thompson Learning, 2007, p. 103.
} 
São maneiras de existir de certo modo opostas, paradoxais, que se alternam constantemente no decorrer de nossa vida, às vezes tão próximas que chegam a se entrelaçar ${ }^{21}$.

\section{Há Sentido no Sofrimento?}

No campo teológico e psicológico da análise e compreensão da saúde mental há um termo que reclama seu espaço: o sofrimento humano. Contrariamente à uma transversalidade do conceito de saúde, o sofrimento se apresenta como um elemento genuinamente constitutivo da existência humana.

A distinção entre o sofrimento como expressão da finitude e o sofrimento como resultado da alienação é válida mesmo que nunca possamos afirmá-la concretamente, por causa da ambiguidade que caracteriza a vida como vida. Mas podemos falar do tipo de sofrimento em que podemos perceber um sentido, em contraste, por exemplo, com o sofrimento que carece de sentido. O sofrimento tem sentido na medida em que reclama proteção e cura no ser que é atacado pela dor. Ele pode mostrar os limites e as potencialidades de um ser vivo. Se o sofrimento desempenha ou não essa função depende certamente do caráter objetivo do sofrimento, mas depende também da forma como é suportado pelo sujeito que sofre. Existem formas de sofrimento que destroem no sujeito a possibilidade de atuar como sujeito, como acontece nos casos de destruição psicótica, de condições externas desumanizantes ou de uma diminuição radical da resistência corporal ${ }^{22}$.

Além da conceituação teológica, o padecimento humano também foi objeto da definição e entendimento psicológicos. O sofrimento de certa maneira deixa de ser sofrimento quando a pessoa encontra um

${ }^{21}$ FORGHIERI, Yolanda Cintrão. Aconselhamento terapêutico: origens, fundamentos e prática. São Paulo: Thompson Learning, 2007, p. 103.

22 TILLICH, 2011, p. 364. 
sentido $^{23}$. Seria o sentido do sacrifício? Certamente, sim! Segundo a logoterapia ${ }^{24}$ admite que a principal preocupação da pessoa humana não consiste em obter prazer ou evitar a dor, porém antes em encontrar ou dar um sentido para a própria existência.

É possível tirar um sentido até do sofrimento, embora com esforço; isto significa, portanto, que o sentido potencial da vida é incondicional. Será que com isso quero dizer que o sofrimento seja necessário para se encontrar um sentido? De maneira alguma. $\mathrm{O}$ que quero dizer não é absolutamente que o sofrimento seja necessário, mas que o sentido é possível apesar do sofrimento, ou mesmo através do sofrimento, contanto que este sofrimento seja inevitável, que não possa ser eliminada sua causa, quer biológica, psicológica ou social ${ }^{25}$.

De acordo com a logoterapia, a análise existencial focaliza a luta do ser humano pelo sentido - não apenas o sentido do sofrimento, mas também o sentido da vida ${ }^{26}$. Mesmo porque a vida transcende o sofrimento à medida em que o sujeito transcende o sofrimento inerente à vida.

A questão do sentido dando ao indivíduo uma nova perspectiva em relação à sua capacidade de decidir mesmo quando não é possível encontrar um sentido é aprofundada por Poujol ${ }^{27}$. Ele assegura que, "tendo renunciado a encontrar um sentido para meu sofrimento, vou talvez conseguir lhe dar um sentido" (grifo do autor). É a possibilida-

${ }^{23}$ FRANKL, Viktor Emil. Em busca de sentido: um psicólogo no campo de concentração. $21^{\mathrm{a}}$ ed. Editora Sinodal \& Vozes, São Leopoldo \& Petrópolis, 2005, p. 101.

${ }^{24}$ Escola psicológica de caráter multifacetado de cunho fenomenológico, existencial, humanista e teísta.

${ }^{25}$ FRANKL, 2003, p. 81.

${ }^{26}$ FRANKL, Viktor Emil. Fundamentos Antropológicos da Psicoterapia. Rio de Janeiro: Zahar Editores, 1978.

${ }^{27}$ POUJOL, Jacques \& POUJOL, Claire. Manual de relacionamento de ajuda: conselhos práticos para acompanhamento psicológico e espiritual. Tradução: Norma Cristina Guimarães Braga. São Paulo: Vida Nova, 2006, p. 266. 
de humana de desenvolver uma atitude pró-ativa frente ao sofrimento. O ser humano tem a possibilidade de se transformar, de fazer algo novo mesmo diante da doença e da morte. Ele é absolutamente livre para interpretar e para dar um sentido ao que lhe acontece. A vida encontra sentido por intermédio do ser humano, através da liberdade em interpretar. "Trata-se de recordar à pessoa que ela não é objeto de sua doença e sintoma; que ela é sujeito de sua enfermidade e que pode fazer algo com o que está lhe acontecendo, dando-lhe um sentido"28.

Os sintomas da vida contemporânea marcam corpos e mentes. As doenças psicossomáticas, por exemplo, podem limitar uma pessoa, mas não impedi-la de reescrever sua própria história. "Minha dor permanece a mesma, mas eu me transformo"29. Um sujeito adoecido tem diante de si a liberdade de se "refugiar" sob a sombra do desespero de qualquer patologia ou de tornar-se resiliente e, apesar de suas limitações e fragilidades, lutar pela vida e transformar tanto a si quanto as pessoas ao seu redor e o seu contexto. Poujol ${ }^{30}$ elucida brilhantemente esse conceito quando afirma: “ao dizer 'vou mal, mas vivo bem', a pessoa substitui o desespero pelo afrontamento lúcido e entra em um fecundo processo de renascimento". Portanto, qualquer sintoma físico oupsíquico pode representar ao sujeito uma oportunidade ímpar no sentido de resignificar o sentido de sua vida, bem comose permitir crescerexistencial e espiritualmente.

\section{Aconselhamento Pastoral e Pastores em Aconselhamento}

De acordo com os resultados apresentados pelo levantamento sociodemográfico da pesquisa realizada por ocasião da dissertação de mestrado deste autor em 2012 na cidade de Curitiba, a amostra revelou

\footnotetext{
${ }^{28}$ LELOUP, Jean-Yves. Uma arte de cuidar: estilo alexandrino. Organização: Suzana Beiro. Petrópolis, RJ: Editora Vozes, 2007, p. 25.

${ }^{29}$ POUJOL \& POUJOL, 2006, p. 268.

${ }^{30}$ POUJOL \& POUJOL, 2006, p. 279.
} 
que do total de pastores pentecostais participantes, 66 eram conselheiros pastorais. Isso representa $92 \%$ do total de pastores. Portanto, apenas $8 \%$ não atuavam como conselheiros, conforme gráfico abaixo.

\section{Gráfico 1 - Conselheiro Pastoral}

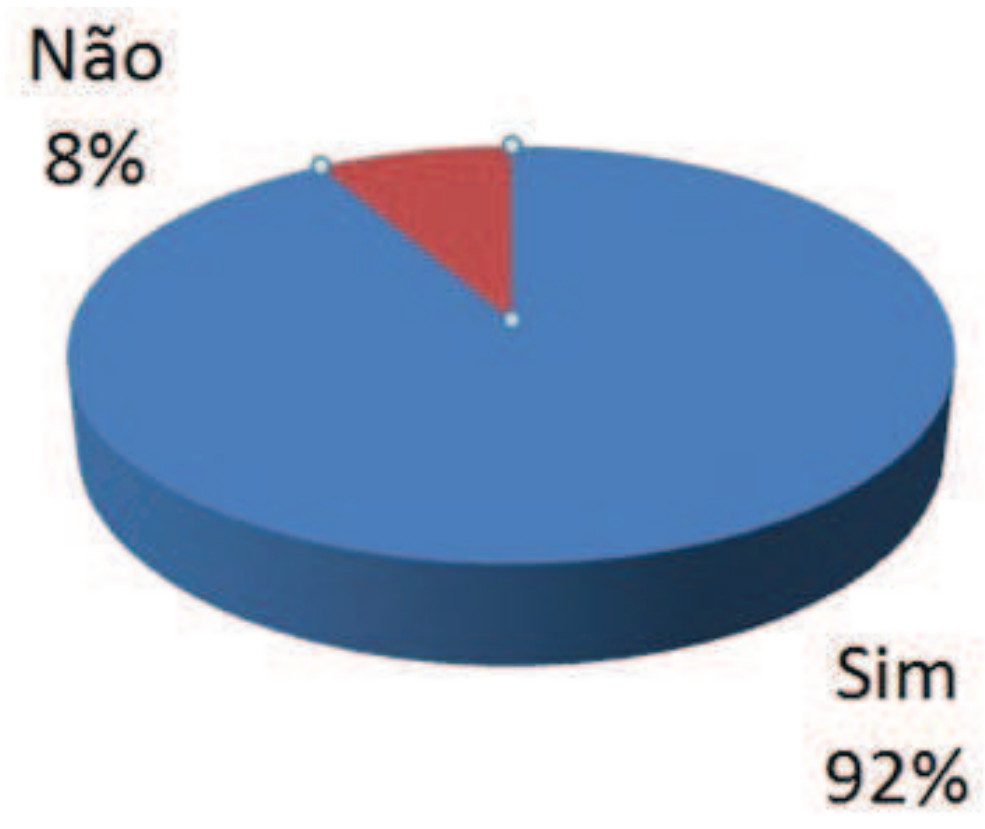

Importante ressaltar que, em função de suas ocupações profissionais, muitos pastores pentecostais não dedicam tempo integral ao sagrado ministério, ocupando os períodos noturnos e fim de semana para a dedicação à igreja local. Evidentemente, o aconselhamento é uma atividade espiritual de suma importância uma vez que o pastor atua tanto como agente de apoio emocional quanto um orientador aos seus liderados a partir de sua própria experiência neste contexto em relação aos fatores de natureza estressora. Além disso, o gabinete pastoral tem-se mostrado como um espaço historicamente legitimado para o encontro e acolhimento empático para a prática do aconselhamento pastoral.

Ressalte-se que, de acordo com a referida pesquisa, a amostra de pastores pentecostais pesquisada não busca regularmente algum tipo de ajuda espiritual, embora atuem na prática do aconselhamento pastoral e tratamento espiritual. Isso parece um tanto paradoxal: ao mesmo tempo em que $92 \%$ dos pastores pentecostais admitem exercer a prática 
do aconselhamento pastoral em seu ministério, boa parte desta amostra não procura auxílio para si, neste sentido.

Com base nesses achados, é fundamental situarmos essa pesquisa a partir dos conceitos teológicos e psicológicos acerca do aconselhamento pastoral.

O aconselhamento constitui-se numa distinção teológica nas páginas sagradas. Parece fundamental percorrer esse caminho conceitual para a compreensão plena dessa práxis ministerial a partir da fundamentação veterotestamentária.

O aconselhamento no AT está centrado na luta do ser humano para resgatar a sua relação com Deus. $\mathrm{O}$ aconselhamento aparece como fenômeno nas diferentes articulações da vida da comunidade, ligado ao culto, ao sistema jurídico e à sabedoria popular. Agentes do aconselhamento no AT são os sacerdotes (Lv 12; 1Sm 1), os anciãos e juízes que tomam decisões em casos de conflitos (Rt 4), os profetas que desenvolvem na sua prática a admoestação e a consolação individual e coletiva (2Sm 12 e Is 40 ) e, em primeiro lugar, os sábios, homens do povo que transmitem como pais de família os conselhos da sabedoria popular para os filhos $(\mathrm{Pv} 4)^{31}$.

Se o aconselhamento no Antigo Testamento está vinculado mais à relação do indivíduo a Deus por meio das instituições estabelecidas no culto espiritual, no Novo Testamento, ele amplia sua abrangência e aprofunda a sua natureza ao incluir componentes espirituais como o amor e o perdão na práxis do acolhimento e orientação espiritual.

No NT observamos a continuação de uma prática que integra cura espiritual e física, aconselhamento, culto, interpretação das leis divinas e sabedoria popular. [Jesus] apresentava-se na sua pregação e prática como reconciliador entre Deus e os seres humanos que representa o amor e o perdão divinos. Esta afirmação dialética da própria identidade perante Deus permaneceu, também após a morte de Jesus na cruz, um elemento essencial da autocompreensão cristã

${ }^{31}$ SCHNEIDER-HARPPRECHT, 1998, p. 295. 
e continua sendo um ponto central para o aconselhamento cristão $0^{32}$

- acréscimo deste autor.

Faz-se necessário frisar que, o pensamento teológico contemporâneo prefere distinguir os termos "poimênica" e "aconselhamento pastoral". Embora sejam correspondentes, os referidos termos não são efetivamente sinônimos, portanto a distinção permite uma melhor compreensão por sua vez.

Definimos a poimênica como o ministério de ajuda da comunidade cristã para os seus membros e para outras pessoas que a procuram na área da saúde através da convivência diária no contexto da Igreja, e definimos o aconselhamento pastoral como uma dimensão da poimênica que procura ajudar através da conversação e outras formas de comunicação metodologicamente refletidas. Ambos baseiam-se na fé cristã e na tradição simbólica do Cristianismo. O objetivo do aconselhamento pastoral é descobrir com as pessoas em diferentes situações da sua vida e especialmente em conflitos e crises o significado concreto da liberdade cristã dos pecadores cujo direito de viver e cuja auto-aceitação vêm da graça de Deus. O seu objetivo é também ajudá-las para que possam viver a relação com Deus, consigo mesmas e com o próximo de uma maneira consciente e adulta ${ }^{33}$.

Portanto, com base nessa definição, o aconselhamento pastoral está diretamente vinculado à poimênica e subordinado a ela. Além disso, duas observações merecem atenção. Em primeiro lugar, o termo "aconselhamento pastoral" é uma expressão etimologicamente traduzida do inglês para o português a partir do termo pastoral counseling, usualmente empregado no contexto norte-americano do século $20^{34}$. E, em segundo lugar, é fundamental identificar as questões relacionadas à agenda da prática do aconselhamento sob uma perspectiva tanto teológica quanto psicológica.

\footnotetext{
32 SCHNEIDER-HARPPRECHT, 1998, pp. 295, 296.

33 SCHNEIDER-HARPPRECHT, 1998, pp. 291, 292.

${ }^{34}$ SCHNEIDER-HARPPRECHT, 1998, p. 291.
} 
Em outras palavras, precisamos afirmar a integridade das disciplinas da psicologia e da teologia. Neste sentido, devemos evitar limitar uma aos termos da outra, mas buscar aumentar ao máximo o potencial de complementaridade entre as contribuições únicas de cada disciplina. Em todo caso, devemos priorizar a natureza teológica e pastoral de nossa tarefa, inclusive refletir sobre a prática do próprio aconselhamento pastoral. Vale enfatizar essa prioridade, devido às diversas maneiras com que a teologia aborda as perguntas fundamentais da vida para, dessa forma, dar subsídios únicos à dimensão normativa do aconselhamento pastoral ${ }^{35}$.

Assim como os diversos recursos empregados no contexto pastoral, o aconselhamento exige um cuidado redobrado em relação à sua prática. A propósito, segundo Schipani ${ }^{36}$, os propósitos do aconselhamento pastoral podem ser enumerados a partir das seguintes situações:

- A experiência ajudou os aconselhandos a encontrarem novas e melhores maneiras de conhecer e entender a realidade de forma multidimensional.

- A experiência encorajou os aconselhandos a descobrirem maneiras mais gratificantes e fiéis de ser e amar, com atenção específica a seu relacionamento com os outros, com Deus e consigo mesmos.

- A experiência capacitou os aconselhandos a fazerem escolhas sensatas e investirem energia renovada em seus relacionamentos, trabalho, lazer, louvor, serviço e a encontrarem maneiras de sustentar essas escolhas com integridade.

Schneider-Harpprecht ${ }^{37}$ aprofunda a questão dos objetivos da prática do aconselhamento pastoral através da experiência relacional ao assegurar que "a convivência e a comunicação são o fundamento social do aconselhamento em geral. $\mathrm{O}$ aconselhamento pastoral é uma

\footnotetext{
${ }^{35}$ SCHIPANI, Daniel S. O Caminho da Sabedoria no Aconselhamento Pastoral. Tradução: Paul Tornquist. São Leopoldo: Sinodal, 2003, p. 32.

${ }^{36}$ SCHIPANI, 2003, pp. 33-35.

${ }^{37}$ SCHNEIDER-HARPPRECHT, 1998, p. 292.
} 
forma específica do discurso humano". Schipani, por sua vez, insere a cooperação dos agentes espirituais no processo do aconselhamento pastoral.

Sob uma perspectiva teológica, o contexto e o processo do aconselhamento pastoral englobaram mais do que aconselhadores e psicoterapeutas geralmente reconhecem, pelo menos expressamente. [...] Ademais, pressupomos a parceria e a colaboração com o Espírito no processo em que aconselhandos e aconselhador procuram conhecer a natureza específica dos problemas e as melhores maneiras de enfrentá-los criativamente e transformá- $\operatorname{los}^{38}$.

Dessa forma, além do componente sobrenatural, outro aspecto fundamental a observar é que o conselheiro pastoral não pode prescindir dos fundamentos bíblicos, mesmo porque a Palavra de Deus consiste num instrumento valioso e imprescindível para todos os envolvidos nesse contexto: quer conselheiro quer aconselhado.

Encontramos nos textos bíblicos a expressão das mais diversas experiências humanas perante Deus e a mensagem do evangelho libertador de Deus. Assim, ela serve para que aconselhando e aconselhador possam enxergar a sua situação simbolicamente refletida no texto bíblico e receber impulsos transformadores que os levem a reconhecer seus erros, ajudem a expressar a dor (catarse), a identificar problemas, buscar normas para o agir, etc. O princípio para o uso da Bíblia é que ela ajuda na simbolização da situação do aconselhando e o liberte para agir nessa situação a partir da fé é $^{39}$.

Para Schneider-Harpprecht ${ }^{40}$, a base social do aconselhamento pastoral consiste fundamentalmente na convivência eclesiástica, ou seja, na experimentação da koinonia dos membros e pessoas que se relacionam integralmente no Corpo de Cristo - a igreja.

\footnotetext{
${ }^{38}$ SCHIPANI, 2003, p. 36.

${ }^{39}$ SCHNEIDER-HARPPRECHT, 1998, p. 317.

${ }^{40}$ SCHNEIDER-HARPPRECHT, 1998.
} 
Esta koinonia tem para os cristãos um significado espiritual: na convivência da comunidade acontece a comunhão com Jesus Cristo, o Filho de Deus encarnado que, na sua vida e morte, compartilhou o destino humano e, conforme a promessa do evangelho, se torna presente 'onde dois ou três se reúnem no nome dele' (Mt 18.20). A metáfora bíblica da Igreja como corpo de Cristo provavelmente é a expressão mais exata para a interdependência das relações humanas e da relação espiritual com Cristo na comunhão dos membros da comunidade cristã ${ }^{41}$.

Finalmente, o conselheiro pastoral deve ter consciência da necessidade do esvaziamento de si para o envolvimento com o outro (com base no conceito cristão de kenosis ${ }^{42}$ ). Ele precisa saber acolher empaticamente o sofrimento do outro, mas sem guardá-lo consigo mesmo. Mesmo porque ele confronta-se diária e constantemente com documentos humanos vivos e, "se for capaz de lê-los, compreendê-los e fazer deles uma fonte constante de reflexão teológica, sua vida pode ser sempre nova, surpreendente, inspiradora e criativa" ${ }^{43}$. É a reescrita da vida a despeito do sofrimento.

\section{Considerações finais}

O relato bíblico das experiências espirituais dos sujeitos no Antigo Testamento e das comunidades religiosas a partir do Novo Testamento revela distintamente as bases conceituais para a práxis do aconselhamento pastoral na igreja atual. A rigor, o contexto eclesiástico-ministerial do pastoreio, o qual inclui evidentemente o aconselhamento cristão, supõe-se que esta práxis bíblico-espiritual ofereça subsídios tanto para uma reflexão teológica quanto para uma proposta de revisão conceitual e estrutural dessa realidade. Mesmo porque, "o aconselhamento pasto-

${ }^{41}$ SCHNEIDER-HARPPRECHT, 1998, p. 292.

${ }^{42}$ Kenosis: conceito da teologia cristã que trata do esvaziamento da vontade própria de uma pessoa e, consequentemente a aceitação da vontade divina. O melhor exemplo é a pessoa e ministério de Jesus.

${ }^{43}$ NOUWEN, Henri J. Intimidade: ensaios de psicologia pastoral. 2a . ed. Tradução: Emerson Lalucce Ricci. São Paulo: Edições Loyola, 2001, p. 117. 
ral é uma forma específica de discurso humano no contexto da Igreja inserida numa determinada sociedade, cultura e tradição" 44 .

$\mathrm{Na}$ teologia bíblica, Cristo é mediador na medida em que reconcilia as pessoas a Deus. "Ele representa Deus diante dos seres humanos e os seres humanos diante de Deus. Ambos os elementos da ideia de mediador foram atribuídos a Jesus como o Cristo" 45 . Através da face de Cristo a humanidade conhece o rosto de Deus; e através do processo de mediação do aconselhamento os conselheiros refletem o rosto de Cristo aos aconselhados. Nisso os agentes do aconselhamento experimentam a vontade reconciliadora de Deus. Portanto, aconselhamento pressupõe tanto mediação quanto reconciliação.

Histórica e culturalmente, o lugar que o conselheiro pastoral ocupa nesse contexto é o de acolhedor de pessoas e de mediador de conflitos;tanto numa perspectiva vertical (entre os aconselhados e Deus), quanto numa perspectiva horizontal(entre pessoas em situações de instabilidade emocional e espiritual, principalmente).

Finalmente, e não menos importante, é o fato de o conselheiro pastoral raramente dispor de pastoreio de si. Em outras palavras, o conselheiro pastoral tem iguais necessidades de ser aconselhado por outro pastor. Pastor pastoreia, mas pastor necessita também ser pastoreado!

Entretanto, percebe-se a necessidade de uma pastoral do cuidado a quem cuida. Uma pastoral do conselho a quem aconselha. Portanto, deve ser resgatado o cuidado integral o qual deve ser uma realidade para todos os que estão envolvidos no trabalho do cuidado e do acolhimento, incluindo aí, evidentemente os conselheiros pastorais. Talvez seja o momento de o conselheiro ouvir menos (seus aconselhados) e falar mais (a seu conselheiro).

Sendo assim, urge a implementação de canais, projetos, programas, ministérios e outros recursos para identificar, socorrer e abrigar os "conselheiros com conselho", ou melhor, "conselheiros em busca de conselho". Essa mudança de perspectiva recolocará o conselheiro no seu devido lugar, o lugar da sua humanidade.

\footnotetext{
${ }^{44}$ SCHNEIDER-HARPPRECHT, 1998, p. 293.

45 TILLICH, 2011, p. 454.
} 


\section{Referências}

ALETTI, Mario. Atendimento psicológico e direção espiritual: semelhanças, diferenças, integrações e... confusões. Psicologias: Teoria e Pesquisa. Vol. 24, n. 1, 2008, pp. 117-126.

DIAS, Agemir de Carvalho. Religião e saúde: uma contribuição evangélica. Revista Pistis\&Praxis - Teologia e Pastoral. Curitiba, v. 2, n. 1, jan./jun, 2010, pp. 127-143.

FARIA, Juliana Bernardes de \& SEIDL, Eliane Maria Fleury. Religiosidade e enfrentamento em contextos de saúde e doença: revisão da literatura. Psicologia: Reflexão e Crítica. Universidade de Brasília. vol.18, n.3,2005, pp. 381-389. Disponível em: http://www.scielo.br/ scielo.php?script $=$ sci arttext\&pid $=$ S0102-79722005000300012\&ln $\mathrm{g}=\mathrm{pt \& nrm}=$ iso\&tlng=pt. Acesso em: 17 fev. 2012.

FORGHIERI, Yolanda Cintrão. Aconselhamento terapêutico: origens, fundamentos e prática. São Paulo: Thompson Learning, 2007.

FRANKL, Viktor Emil. Fundamentos Antropológicos da Psicoterapia. Rio de Janeiro: Zahar Editores, 1978.

FRANKL, Viktor Emil. A presença ignorada de Deus. Tradução: Walter O. Schlupp e Helga H. Reinhold. São Leopoldo \& Petrópolis, Editora Sinodal \& Vozes, 2003.

FRANKL, Viktor Emil. Em busca de sentido: um psicólogo no campo de concentração. $21^{\mathrm{a}}$. ed. São Leopoldo \& Petrópolis, Editora Sinodal \& Vozes, 2005.

HOLANDA, Adriano. Psicologia, religiosidade e fenomenologia. Organizador. Campinas: Editora Alínea, 2004.

LELOUP, Jean-Yves. Uma arte de cuidar: estilo alexandrino. Organização: Suzana Beiro. Petrópolis: Editora Vozes, 2007.

MOREIRA, Neir\& HOLANDA, Adriano. Logoterapia e o sentido do sofrimento: convergências nas dimensões espiritual e religiosa. RevistaPsico-USF [on line].Vol. 15, n. 3, set/dez 2010, pp. 345-356. Acesso em 08 de maio de 2012.

NOUWEN, Henri J. Intimidade: ensaios de psicologia pastoral. $2^{a}$ edição. Tradução: Emerson Lalucce Ricci. São Paulo: Edições Loyola, 2001. 
POUJOL, Jacques\&POUJOL, Claire. Manual de relacionamento de ajuda: conselhos práticos para acompanhamento psicológico e espiritual. Tradução: Norma Cristina Guimarães Braga. São Paulo: Vida Nova, 2006.

ROSA, Merval. Psicologia da religião. Rio de Janeiro: JUERP, 1992.

SCHIPANI, Daniel S. O Caminho da Sabedoria no AconselhamentoPastoral. Tradução: Paul Tornquist. São Leopoldo: Editora Sinodal, 2003.

SCHNEIDER-HARPPRECHT, Christoph(org.).Teologia Prática no Contexto da América Latina. São Leopoldo: Editora Sinodal/ ASTE, 1998.

SUDBRACK, Josef. Experiência religiosa e psique humana: onde a religião e a psicologia se encontram. Tradução: FredericusAntonius Stein. São Paulo: Edições Loyola, 2001.

TILLICH, Paul. Teologia Sistemática. Tradução: Getúlio Bertelli e Geraldo Korndörfer. São Leopoldo: Editora Sinodal, 2011. 